\title{
The role of cAMP in synaptic homeostasis in response to environmental temperature challenges and hyperexcitability mutations
}

\author{
Atsushi Ueda and Chun-Fang Wu * \\ Department of Biology, University of lowa, lowa City, IA, USA
}

Edited by:

Jaichandar Subramanian,

Massachusetts Institute of

Technology, USA

Reviewed by:

Subhabrata Sanyal, Emory

University, USA

Mani Ramaswami, Trinity College

Dublin, Afghanistan

*Correspondence:

Chun-Fang Wu, Department of

Biology, University of lowa, 129

E. Jefferson St., Biology Building,

Room 231, lowa City,

IA 52242, USA

e-mail: chun-fang-wu@

uiowa.edu
Homeostasis is the ability of physiological systems to regain functional balance following environment or experimental insults and synaptic homeostasis has been demonstrated in various species following genetic or pharmacological disruptions. Among environmental challenges, homeostatic responses to temperature extremes are critical to animal survival under natural conditions. We previously reported that axon terminal arborization in Drosophila larval neuromuscular junctions (NMJs) is enhanced at elevated temperatures; however, the amplitude of excitatory junctional potentials (EJPs) remains unaltered despite the increase in synaptic bouton numbers. Here we determine the cellular basis of this homeostatic adjustment in larvae reared at high temperature $\left(H T, 29^{\circ} \mathrm{C}\right)$. We found that synaptic current focally recorded from individual synaptic boutons was unaffected by rearing temperature $\left(<15^{\circ} \mathrm{C}\right.$ to $\left.>30^{\circ} \mathrm{C}\right)$. However, HT rearing decreased the quantal size (amplitude of spontaneous miniature EJPs, or mEJPs), which compensates for the increased number of synaptic releasing sites to retain a normal EJP size. The quantal size decrease is accounted for by a decrease in input resistance of the postsynaptic muscle fiber, indicating an increase in membrane area that matches the synaptic growth at HT. Interestingly, a mutation in rutabaga (rut) encoding adenylyl cyclase (AC) exhibited no obvious changes in quantal size or input resistance of postsynaptic muscle cells after HT rearing, suggesting an important role for rut AC in temperature-induced synaptic homeostasis in Drosophila. This extends our previous finding of rut-dependent synaptic homeostasis in hyperexcitable mutants, e.g., slowpoke (slo). In slo larvae, the lack of BK channel function is partially ameliorated by upregulation of presynaptic Shaker (Sh) IA current to limit excessive transmitter release in addition to postsynaptic glutamate receptor recomposition that reduces the quantal size.

Keywords: rutabaga adenylyl cyclase, quantal size, input resistance, synaptic growth, quantal content

\section{INTRODUCTION}

Homeostatic mechanisms are involved in the striking ability of regaining stable synaptic efficacy or neural circuit performance following disturbances caused by environmental stressors or experimental insults in the nervous systems of a variety of species (Turrigiano and Nelson, 2004; Pérez-Otaño and Ehlers, 2005; Davis, 2006; Marder and Goaillard, 2006). In mammals, pharmacological manipulations of neuronal spiking or synaptic activities have been shown to cause compensatory changes in synaptic strength. For example, the blockade of action potentials by Tetrodotoxin (TTX) or postsynaptic inhibition by receptor antagonists can result in striking increases in spontaneous excitatory synaptic currents (EPSCs), as observed in dissociated cultures of cortical neurons (Turrigiano et al., 1998), hippocampal slices (Rao and Craig, 1997; Lissin et al., 1998), and in vivo recordings of visual cortical neurons (Desai et al., 2002) and spinal neurons (O'Brien et al., 1998). In some cases, the compensatory response is mediated through upregulation of receptor subtype expression (Watt et al., 2000; Leslie et al., 2001). However, the underlying general regulatory mechanisms and detailed molecular networks still await further elucidation.

A naturally occurring and ecologically relevant stressor that induces neuronal homeostatic adjustment is environmental temperature. Chronic temperature changes are known to affect neuronal development, leading to neuronal morphological alterations, such as neuronal dendritic field retraction during hibernation in ground squirrels (Popov and Bocharova, 1992; Popov et al., 1992; von der Ohe et al., 2006) or dendritic spine number reduction following short-term decreases in local temperature in the mouse brain (Kirov et al., 2004; Roelandse and Matus, 2004). Synaptic homeostatic adjustments also maintain the stability of physiological functions upon drastic temperature changes. For instance, in the stomatogastric ganglion of the crab phase relationships between action potential bursts characteristic to individual identified neurons are maintained 
despite temperature changes that significantly alter the neuronal firing rate within the central pattern generators (Tang et al., 2010, 2012). It is also known that after long-term exposure to extreme temperatures, neurons display adjustments in various physiological parameters, such as resting membrane potential and EPSP amplitude, in a number of species (fish: Roots and Prosser, 1962; Friedlander et al., 1976; snail: Merickel and Kater, 1974; crayfish: Harri and Florey, 1979; honeybee: Tautz et al., 2003; Groh et al., 2004; Jones et al., 2005).

The Drosophila larval neuromuscular junction (NMJ) offers abundant opportunities for studying the molecular and genetic mechanisms underlying synaptic homeostasis (Davis and Bezprozvanny, 2001 for review). It has been documented in Drosophila that axon terminal arborization is enhanced at increased temperatures (Sigrist et al., 2003; Zhong and Wu, 2004; Peng et al., 2007; Lee and Wu, 2010). These temperatureinduced morphological alterations can be further modulated by mutations altering neuronal excitability: drastic increases by $\mathrm{K}^{+}$channel mutations (Budnik et al., 1990; Zhong et al., 1992) and decreases by $\mathrm{Ca}^{2+}$ channel mutations (Lee and $\mathrm{Wu}$, 2010). Significantly, such morphological modifications induced by increased temperature or neuronal hyperexcitability can be suppressed by a mutation in rutabaga (rut) encoding adenylyl cyclase (AC), implicating the involvement of the cAMP pathway in the plasticity of synaptic growth (Zhong et al., 1992; Lee and Wu, 2010).

Here we examine the physiological parameters of pre- and post-synaptic elements to identify the temperature-dependent alterations in maintaining. Such counterbalancing modifications enable the maintenance of stable synaptic transmission at the Drosophila larval NMJ upon high temperature (HT) rearing. In spite of the increased number of synaptic boutons, the excitatory junctional potential (EJP) size remains unaltered. Strikingly, this temperature-induced synaptic homeostasis was not observed in mutant larvae with impaired function of rut AC following HT rearing.

\section{MATERIALS AND METHODS DROSOPHILA STOCKS}

The Drosophila melanogaster stocks used include a wild-type (WT) strain Canton-S and a mutant rutabaga ${ }^{1}\left(\right.$ rut $\left.^{1}\right)$. These lines have been previously described (Zhong et al., 1992; Kim and Wu, 1996; Renger et al., 2000; Peng et al., 2007). Flies carrying UAS-rut ${ }^{+}$was a generous gift from Dr. Troy Zars (University of Missouri, Columbia, MO, USA; Zars et al., 2000). A motor neuron-specific driver C164-Gal4 (Torroja et al., 1999) and muscle-specific driver mef2-Gal4 (Ranganayakulu et al., 1996) were used to drive expression of the transgene.

Fly stocks were maintained at room temperature (RT). However, the building RT varied significantly over the seasons between 1997 and 2001, as low as $15^{\circ} \mathrm{C}$ during winter and as high as $30^{\circ} \mathrm{C}$ during summer. Focal recording was carried out during this period. Experiments on rearing temperature effects and intracellular recording of EJP were performed after 2002 when the building temperature was maintained at $22-24^{\circ} \mathrm{C}$ throughout the year. To examine the effect of rearing temperature, we compared the stocks maintained at RT with those reared in $29-30^{\circ} \mathrm{C}$ incubators.

\section{LARVAL NEUROMUSCULAR PREPARATIONS AND PHYSIOLOGICAL SOLUTIONS}

Post-feeding third instar larvae were dissected in $\mathrm{Ca}^{2+}$ free HL3 saline (Stewart et al., 1994) containing (in $\mathrm{mM}$ ) $70 \mathrm{NaCl}$, $5 \mathrm{KCl}, 20 \mathrm{MgCl}_{2}, 10 \mathrm{NaHCO}_{3}, 5$ Trehalose, 115 Sucrose, and 5 HEPES, at $\mathrm{pH}$ 7.2. For physiological recordings, we used either HL3 (focal recording in Figures 2, 4) or HL3.1 (Feng et al., 2004), which have the same ionic composition except for a reduced $\mathrm{Mg}^{2+}$ concentration in HL3.1 (4 mM, whole cell intracellular recordings, Figures 1, 3, 5, 6). The final $\mathrm{Ca}^{2+}$ concentration in recording saline is specified for each experiment. To evoke nerve action potentials and excitatory junctional currents (EJCs), the segmental nerves were severed from the ventral ganglion and stimulated with a suction electrode $(10 \mu \mathrm{m}$ inner diameter $)$ through the cut end. Stimulation amplitude was adjusted to 2.0-2.5 times the threshold voltage to ensure a uniform stimulation condition among experiments. Stimulus duration was 0.1 or $0.5 \mathrm{~ms}$.

\section{FOCAL LOOSE PATCH-CLAMP RECORDING}

Extracellular focal recordings were performed as described previously (Renger et al., 2000; Ueda and Wu, 2009). Briefly, fire-polished focal recording electrodes with an inner diameter of 4-8 $\mu \mathrm{m}$ and an outer diameter of 15-20 $\mu \mathrm{m}$ were filled with HL3 saline and were placed over type I boutons on muscle 13. The pipette opening typically covered one type Ib bouton. EJC signals were picked up with a loose-patch clamp amplifier (Patch Clamp 8510; Zeitz Instruments, Munich, Germany) and stored on VCR tapes with a Pulse Code Modulator (Neuro Data, model Neuro-Corder DR-384, New York, NY). All trials contained a calibration pulse to determine the electrode series and seal resistance in order to correct for current leakage at the pipette tip (Stühmer et al., 1983). In rare occasions, biphasic currents were observed, but they were excluded from data analysis.

\section{WHOLE-CELL EXCITATORY JUNCTIONAL POTENTIAL (EJP) AND MUSCLE INPUT RESISTANCE MEASUREMENTS}

Nerve-evoked neurotransmitter release was also recorded intracellularly from postsynaptic muscle fiber 6. Intracellular glass microelectrodes were filled with $3 \mathrm{M} \mathrm{KCl}$ and had a series resistance of about $60 \mathrm{M} \Omega$. EJPs were picked up with a direct current pre-amplifier (model M701 micro-probe system, WPI, Conn., USA, and an additional custom-built amplifier). Muscle membrane resistance was measured by injecting $-1 \mathrm{nA}$ current pulses with $700 \mathrm{~ms}$ duration into a muscle cell. A bridge circuit was used to measure the membrane potential change. We selected cells with resting potentials deeper than $-55 \mathrm{mV}$ for evoked EJPs and muscle input resistance measurement. For miniature EJP (mEJP) measurement, we selected cells with resting potentials deeper than $-60 \mathrm{mV}$ to ensure minimal membrane damage caused by electrode penetrations. 


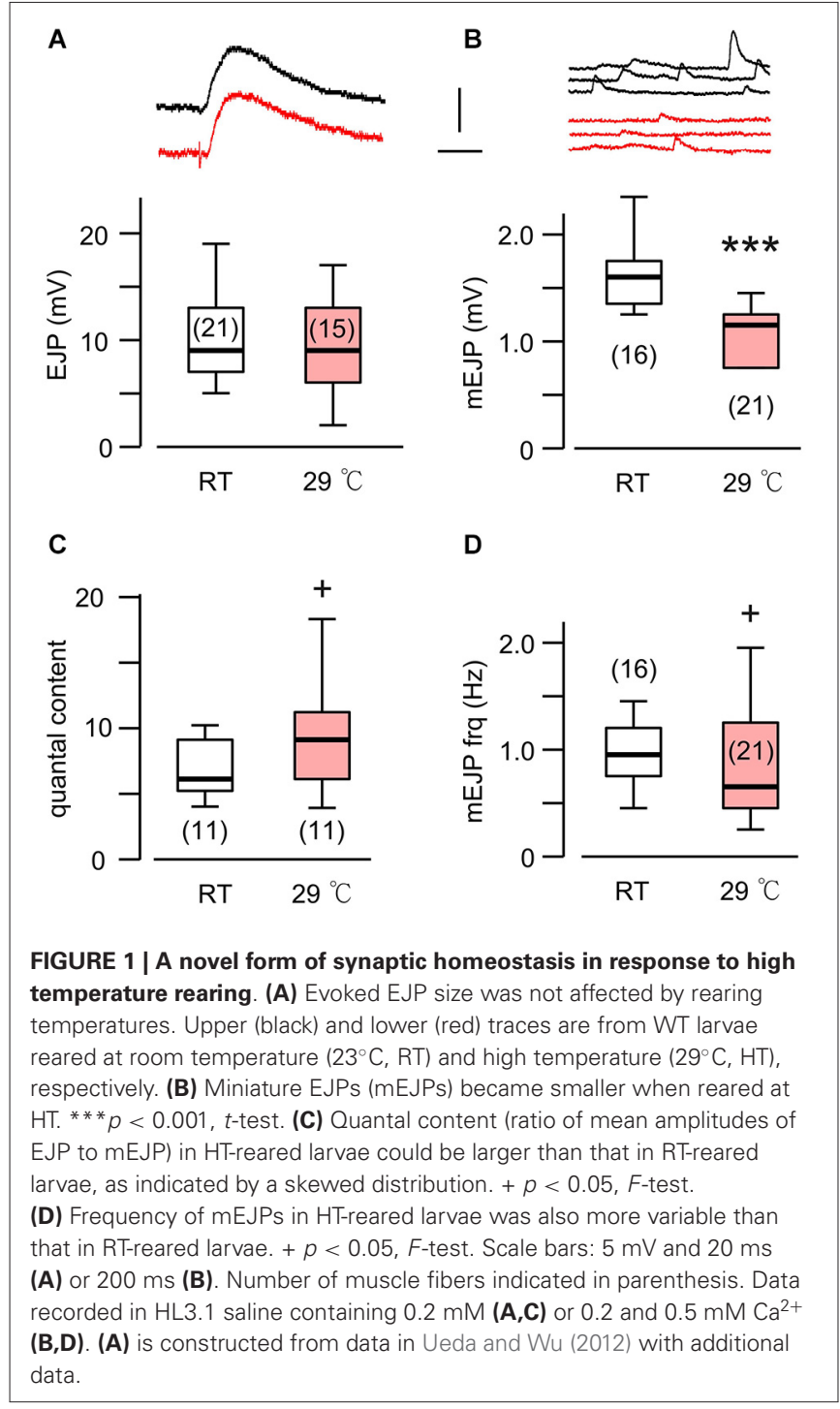

\section{STATISTICAL ANALYSIS}

As described in the Results, ANOVA, F-test, Wilcoxon ranksum test, and student $t$-test were carried out with sequential Bonferroni adjustment for multiple comparisons.

\section{RESULTS \\ HOMEOSTASIS OF SYNAPTIC EFFICACY UPON HT REARING: MAINTAINED EJP AMPLITUDE WITH INCREASED BOUTON NUMBERS AND REDUCED mEJP SIZE}

It is now well established that $\mathrm{HT}$ rearing (at $29^{\circ} \mathrm{C}$ ) induces synaptic terminal overgrowth resulting in an increased number of presynaptic boutons at the Drosophila larval NMJ (Sigrist et al., 2003; Zhong and Wu, 2004; Lee and Wu, 2010). However, the synaptic strength, as determined by the amplitude of the EJPs in the postsynaptic muscle cell, remains unaltered compared to that in larvae reared at RT (Figure 1A; Ueda and $\mathrm{Wu}, 2012$ ). This raises the question of how the number of presynaptic vesicles released from individual boutons and the postsynaptic response to individual vesicles are adjusted

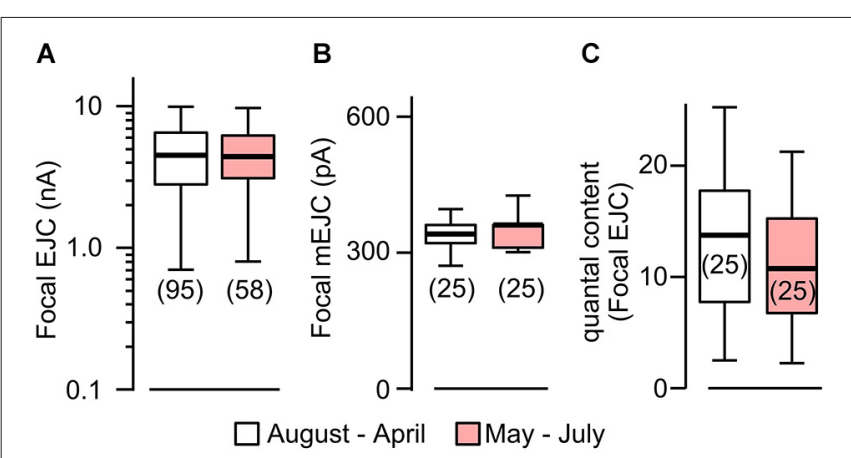

FIGURE 2 | Focal mEJCs and EJCs were not affected by rearing temperature. Focal EJCs (A) and mEJCs (B) remained stable despite ambient temperature fluctuations. Building temperature varied significantly: from as low as $15^{\circ} \mathrm{C}$ to beyond $30^{\circ} \mathrm{C}$ (mostly during May to July). Pooled data from August to April are compared to those from May to July. (C) Quantal content of the focal EJCs was not different between the two periods ( $p>0.5$, Wilcoxon rank-sum test). Number of recording sites indicated in parenthesis. $(\mathbf{A})$ is reconstructed from data in Ueda and Wu (2012).

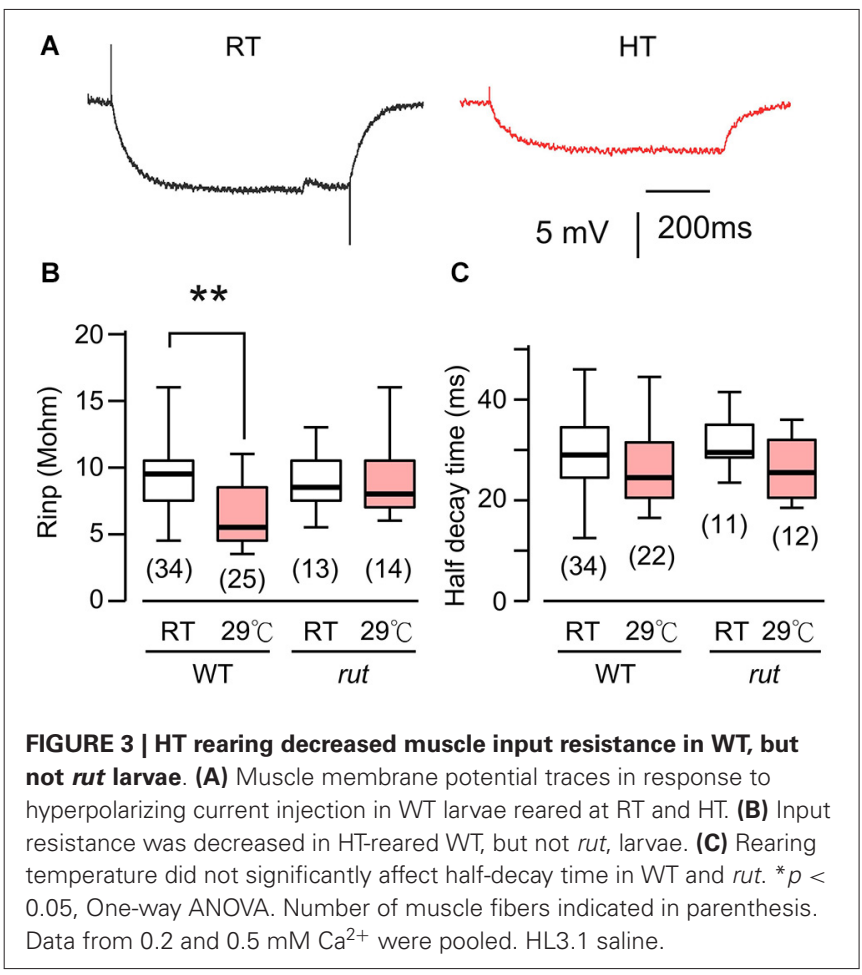

in order to maintain stable synaptic efficacy when reared at HT. To answer this question, we first carried out intracellular recording to measure the muscle whole-cell response (EJP) and the spontaneous miniature EJPs (mEJPs), which reflect the postsynaptic response to spontaneous release of single vesicles (quantal size, Figure 1B). These parameters allowed us to estimate the quantal content, i.e., the number of vesicles released, underlying each EJP.

We used saline containing low $\mathrm{Ca}^{2+}(0.2 \mathrm{mM})$, at which the summation of mEJPs is nearly linear, circumventing the 


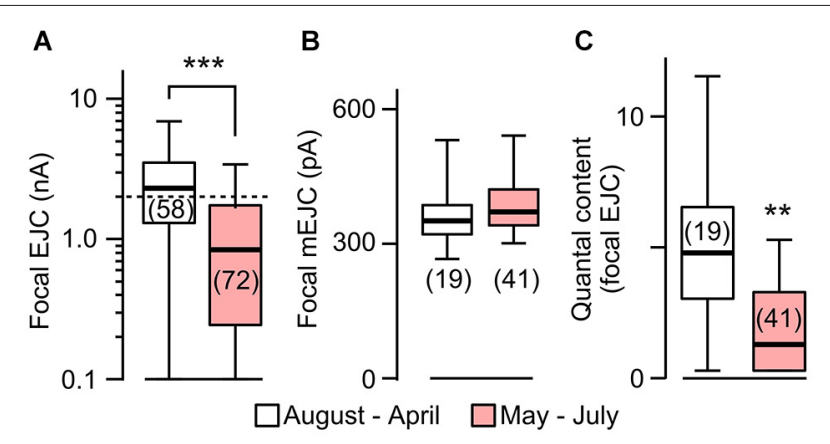

FIGURE 4 | Focal EJC amplitudes affected by rearing temperature in rut. (A) Focal EJCs from the great majority of rut boutons were below $2 \mathrm{nA}$ (dotted line) during the period of May to July, whereas those collected outside of this period were substantially larger. Compare to Figure $\mathbf{2}$ for constant EJC size for WT. (B) Focal mEJC amplitudes in rut did not vary with ambient temperature fluctuations. (C) Quantal content was significantly smaller at HT. Number of recording sites indicated in parenthesis. ${ }^{* *} p<0.001$; ${ }^{* *} p<0.01$, Wilcoxon rank-sum test. (A) is reconstructed from data in Ueda and Wu (2012).

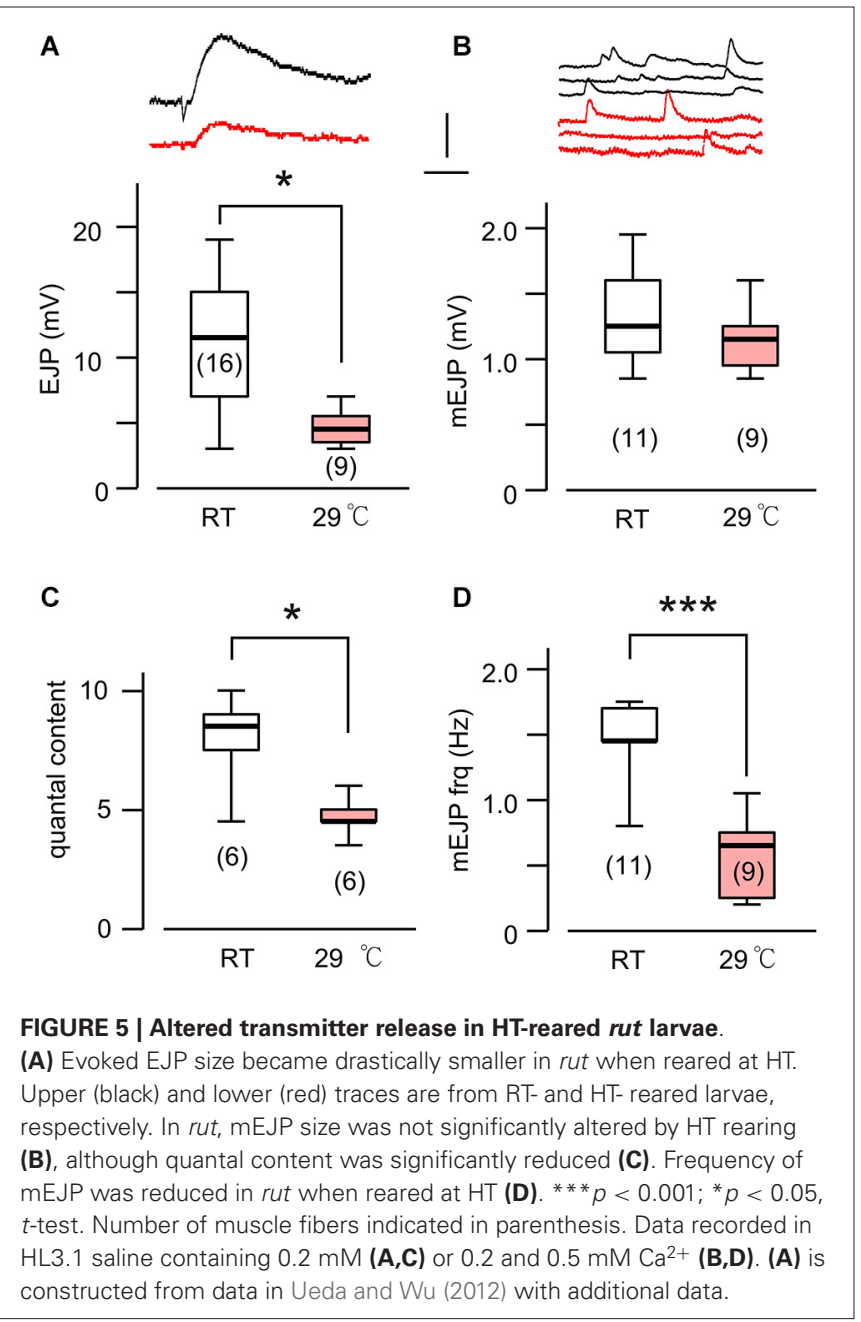

problem of nonlinear summation, allowing for the simple determination of quantal contents by the index $[\mathrm{EJP}] /[\mathrm{mEJP}]$,

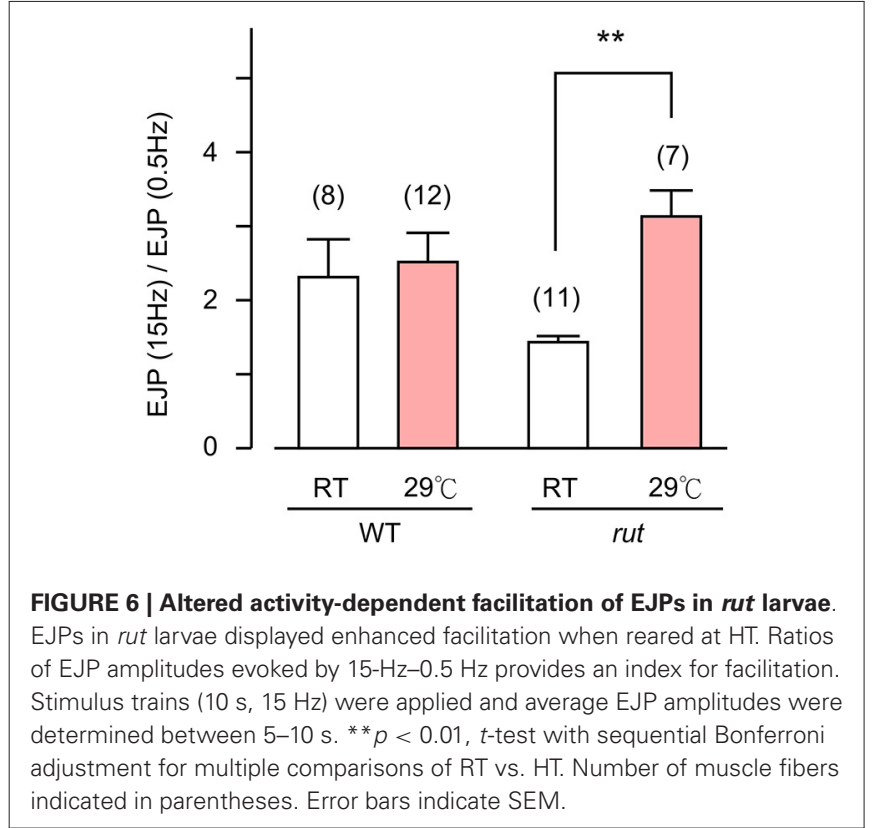

where $[\mathrm{EJP}]$ and $[\mathrm{mEJP}]$ represent the average amplitude of EJPs and mEJPs. Our data collected from muscles 6 and 7 indicate that the quantal size, as determined from the mEJP size, was reduced in WT when reared at HT (Figure 1B). To maintain the same EJP size, this led to an increase in quantal content (Figure 1C). Interestingly, a previous study also reported a similar percentage increase in the number of boutons in muscles 6 and 7 after HT rearing at $29^{\circ} \mathrm{C}$ (Sigrist et al., 2003). Therefore, it is important to investigate how HT-rearing affects the functioning at the synaptic bouton level, in terms of the number of vesicles released upon nerve stimulation and the postsynaptic currents generated by each vesicle in order to account for the ensemble EJP response evoked by each nerve action potential.

\section{REARING-TEMPERATURE EFFECT ON POSTSYNAPTIC CURRENTS GENERATED BY INDIVIDUAL BOUTONS}

We have previously established focal loose-patch recordings to determine local synaptic currents generated from transmitter release within individual boutons (Kurdyak et al., 1994; Renger et al., 2000; Ueda and Wu, 2009, 2012). Using a focal pipet electrode of a standard configuration and size (see Section Materials and Methods), local EJCs, as well as spontaneous miniature EJCs (mEJCs), from boutons under the patch electrode can be determined to complement wholecell intracellular recordings of spontaneous mEJPs and evoked EJPs.

To quantify temperature-induced changes in focal mEJCs and EJCs, we performed loose-patch clamping followed by the established procedure to correct for errors introduced by leakage currents (see Section Materials and Methods; Kurdyak et al., 1994). We took advantage of a large data set collected between 1997-2000, during which ambient temperature for fly rearing and physiological recording varied between different seasons, approaching $30^{\circ} \mathrm{C}$ in the summers and $15^{\circ} \mathrm{C}$ in 
the winters (see Section Materials and Methods; Ueda and Wu, 2012). We followed chronologically the data throughout these years and found no variation in EJC amplitude despite the temperature variation (Figure 2A; Ueda and Wu, 2012). When we performed additional analysis to include mEJC size using the same set of focal recording data, we found that focal mEJC size was also unaltered (Figure 2B). The fact that focal mEJCs remained the same is consistent with the simple interpretation that rearing temperature affects neither the amount of transmitter released per synaptic vesicle, nor the postsynaptic glutamate receptor channel response to each vesicle release. Therefore, unaltered focal EJCs and mEJCs support the conclusion that the quantal content for the local release from each bouton was unaffected by temperature variations (Figure 2C). Overall, this is consistent with the notion that the increased whole-cell quantal content determined by EJP measurements (Figure 1C) simply reflects the increase in presynaptic bouton numbers.

It should be noted that focal mEJCs amplitude did not appear to vary at different $\mathrm{Ca}^{2+}$ levels. Although the focal mEJC analyses in Figure 2 were performed at a physiological $\mathrm{Ca}^{2+}$ level $(1.5 \mathrm{mM})$, the results were compatible with the whole-cell mEJP recording that were collected at a low $\mathrm{Ca}^{2+}$ concentration $(0.2 \mathrm{mM}$, Figure 1 to avoid nonlinear summation distortion, see Section Materials and Methods). Additional focal mEJC measurements performed at a lower $\mathrm{Ca}^{2+}$ concentration $(0.5 \mathrm{mM})$ produced similar results $(330 \pm 67 \mathrm{pA}$ at $0.5 \mathrm{mM}$, $n=10$ fibers vs. $340 \pm 45 \mathrm{pA}$ at $1.5 \mathrm{mM}, n=50$ fibers).

\section{DECREASED POSTSYNAPTIC MUSCLE INPUT RESISTANCE ACCOUNTS FOR mEJP SIZE DECREASE IN HT-REARED LARVAE}

The postsynaptic voltage responses, mEJPs and EJPs, reflect charging of muscle membrane capacitance by the synaptic currents, mEJCs and EJCs. The disparity between the HTrearing effects on $\mathrm{mEJP}$ size and $\mathrm{mEJC}$ size prompted us to examine the passive electrical properties of the postsynaptic muscle fiber (i.e., muscle cell membrane resistance and time constant). To determine these parameters, we measured the voltage response to hyperpolarizing negative current injection of fixed amplitudes $(-1$ to $-2 \mathrm{nA})$. The results showed a significant decrease in muscle input resistance in HT-reared larvae (Figures 3A,B). This indicates that when focal mEJCs remain unaltered, an increase in membrane conductance may be responsible for the diminished mEJPs in HT-reared larvae (Figure 1B). Indeed, we found a positive correlation between input resistance and $\mathrm{mEJP}$ size among individual muscle fibers (correlation coefficient $=0.59, p<0.01$, data not shown). Furthermore, there was no clear indication of changes in the membrane time constants as evidenced by unaltered half decay time upon cessation of hyperpolarizing current injection (Figure 3C). The results suggest no changes in the passive muscle membrane properties (membrane resistance and capacitance per unit area).

Taken together, for the postsynaptic muscle fiber as a functional unit, the whole-cell EJP size is homeostatically maintained after HT rearing. In spite of the increase in synaptic bouton numbers leading to the increase in quantal content
$([\mathrm{EJP}] /[\mathrm{mEJP}])$, stable synaptic strength is maintained through the counterbalancing effect of the decrease in postsynaptic muscle input resistance.

\section{A ROLE OF rUt AC IN SYNAPTIC HOMEOSTASIS: DIMINISHED HT-REARING EFFECTS ON MUSCLE INPUT RESISTANCE AND OUANTAL EVENTS}

Previous Drosophila studies have established a clear role of cAMP in synaptic overgrowth induced by HT rearing or hyperexcitability mutations because mutations in rut AC suppress NMJ arborization or neuronal branching under such conditions (Zhong and Wu, 2004; Peng et al., 2007; Lee and Wu, 2010). Therefore we first examined the muscle input resistance of rut mutant larvae to determine whether the cAMP pathway is also involved in the HT-induced decrease in muscle input resistance. We observed a clearly different response to HT rearing in rut compared to WT larvae. When comparing RT-reared and HT-reared rut larvae, the muscle input resistance and membrane time constant remained unaltered, as evidenced by the similar responses to the same hyperpolarizing current injection (Figures 3B,C).

The above results prompted us to compare the sizes of mEJCs in RT- and HT-reared rut larvae (Figure 4) using loose-patch focal recording. We analyzed the same sets of focal recording data from 1997-2000 (Ueda and Wu, 2012) in parallel with the analysis for WT larvae (Figure 2). The results showed that the quantal unit of transmission, focal mEJCs (Figure 4B), was not altered by HT rearing in rut larvae, similar to the observation in WT larvae. However, synaptic efficacy in rut is drastic reduced by HT rearing, as reflected by diminished focal EJCs (Figure 4A; Ueda and $\mathrm{Wu}$, 2012).

Based on the fact that the bouton number in rut larvae remains unchanged following $\mathrm{HT}$ rearing (Zhong and $\mathrm{Wu}$, 2004), one should be able to predict the properties of EJPs in rut larvae following HT rearing. As a functional unit, the rut muscle fiber would display an unaltered size of quanta (mEJPs) but greatly diminished EJPs coupled with a reduction in quantal content. Our intracellular recording confirmed these predictions. Although the rut EJP amplitude was not significantly different from WT larvae when reared at RT, rut EJPs drastically reduced in size following HT rearing, in striking contrast to the homeostatic maintenance of EJPs in WT (Compare Figures 1A and 5A). Furthermore, following HT rearing the mEJP size remained the same in rut, unlike a reduction in WT (Compare Figures $1 \mathrm{~B}$ and $5 \mathrm{~B}$ ). Correspondingly, HT rearing exerted opposite effects on the quantal content in rut (decrease) vs. WT (increase) (Compare Figures 1C and 5C).

Finally, an examination of the spontaneous mEJP frequency revealed another transmitter release defect caused by rut upon temperature challenges. While HT rearing did not change the $\mathrm{mEJP}$ frequency in WT, there was a drastic decrease in spontaneous mEJP frequency in rut (Compare Figures 1D and 5D). More extensive temperature-dependent defects in rut were also evident in short-term activity-dependent plasticity following HT rearing. Using a synaptic augmentation protocol (Zhong and Wu, 1991; Renger et al., 2000) with 
high-frequency nerve stimulation (15 Hz, $10 \mathrm{~s}, 0.2 \mathrm{mM}$ $\mathrm{Ca}^{2+}$ ), rut larvae displayed drastically increased augmentation following HT rearing, whereas WT larvae retained the same augmentation properties. Therefore, short-term synaptic plasticity is also maintained in HT-reared WT larvae but disrupted in rut larvae with a striking enhancement of activity-dependent synaptic facilitation following HT rearing (Figure 6).

Our previous study has manipulated the expression of rut AC separately in pre- and post-synaptic compartments to examine the consequences on rut morphological phenotypes. With targeted expression of UAS-rut ${ }^{+}$by neuron- or musclespecific Gal4 drivers, it has been shown that the HT-induced NMJ overgrowth can be rescued by neuronal, but not muscular, expression of $\mathrm{rut}^{+}$(Zhong and $\mathrm{Wu}, 2004$ ). Here we asked how pre- or post-synaptic expression of $\mathrm{rut}^{+}$modifies the defective synaptic homeostasis in HT-reared rut larvae. To express rut ${ }^{+}$ in motor neurons and muscles in $r^{1} t^{1}$ mutant background, we drove UAS-rut ${ }^{+}$expression by C164-Gal4 (Torroja et al., 1999) and mef2-Gal4 drivers (Ranganayakulu et al., 1996), respectively. We found that neither driver could totally rescue the $r u t^{1}$ phenotypes. Nevertheless, overexpression of $r u t^{+}$in muscle restored one aspect of the HT-induced homeostasis, i.e., EJP amplitude adjustment, but it did not modify muscle input resistance to mimic the WT response. In contrast, presynaptic overexpression of $\mathrm{rut}^{+}$in motor neurons did not rescue either of the HT-induced homeostasis.

For EJP amplitudes, muscle expression of $\mathrm{rut}^{+}$appeared to rescue the homeostatic maintenance $(15.4 \pm 4.2$ and $16.6 \pm 4.7$ $\mathrm{mV}, n=8$ and 7 fibers, respectively, for RT and HT rearing, $p>$ 0.05 with $t$-test), whereas expression of $\mathrm{rut}^{+}$in motor neurons lead to no restoration $(21.6 \pm 6.0$ and $12.9 \pm 7.7 \mathrm{mV}, n=7$ and $7, p<0.05)$. For the case of muscle input resistance, neither neuronal or muscle expression of $\mathrm{rut}^{+}$could rescue the expected HT-induced decrease, as seen in WT (neuronal expression: 7.8 \pm 3.3 and $8.5 \pm 2.5$ Mohm, $n=13$ and 15, $p>0.05$; muscle expression: $7.3 \pm 1.9$ and $6.5 \pm 2.0 \mathrm{Mohm}, n=15$ and 15, $p>0.05)$.

\section{DISCUSSION}

\section{SYNAPTIC HOMEOSTASIS AT THE DROSOPHILA NMJ}

The Drosophila larval NMJ has been widely used for studying the genetic and molecular mechanisms underlying synaptic transmission and plasticity. Our study highlights a distinct category of synaptic homeostasis in response to environmental temperature stress. Our finding also indicates the involvement of the cAMP pathway in this form of homeostatic adjustment, further illustrating the important role of cAMP previously implicated in the various forms of synaptic and behavioral plasticity in Drosophila (Engel and Wu, 2009; Bushey and Cirelli, 2011; Kahsai and Zars, 2011; Ueda and Wu, 2012).

The first documented case of synaptic homeostasis at the Drosophila larval NMJ originates from a reduction in synaptic bouton numbers in mutants of the cell adhesion molecule Fasculin II (Stewart et al., 1996). This severe developmental alteration of the NMJ size nevertheless does not change the EJP amplitude, due to a compensatory increase in neurotransmitter release from individual synaptic boutons. Subsequent studies based on manipulations to decrease the postsynaptic quantal response further demonstrate the robust homeostatic adjustment in transmitter release at larval NMJs. Compensatory increases in the number of synaptic vesicle release (i.e., quantal content) occurs when the mEJP amplitude (quantal size) is diminished following either mutational disruption (Petersen et al., 1997; DiAntonio et al., 1999) or pharmacological blockade (Frank et al., 2006) of the postsynaptic glutamate receptors. In addition, when the mEJP amplitude is diminished due to a decrease in muscle input resistance by forced expression of inward rectifier $\mathrm{K}^{+}$channels (Kir; Baines et al., 2001), synaptic vesicle release from individual boutons is also homeostatically upregulated to maintain a stable EJP amplitude (Paradis et al., 2001).

A mechanism of retrograde trans-synaptic signaling via yet to be identified postsynaptic factors has been implicated in further studies. However, these studies also indicate that bone morphogenesis protein (BMP), encoded by glassbottom boat $(g b b)$, is required for synaptic homeostasis (Goold and Davis, 2007; Frank et al., 2009). The action of BMP during the early phases of embryonic and larval development enables the HTand hyperexcitability-induced synaptic growth that occurs at later stages of larval development (Berke et al., 2013). In addition, a number of presynaptic proteins also participate in the regulation of synaptic homeostasis, including Ephexin, a Rho-type guanine nucleotide exchange factor (Frank et al., 2009), cacophonyencoded voltage-gated calcium channels, (Frank et al., 2009; Müller and Davis, 2012; Lee et al., 2013), and a GTPase-activating protein Rab3 (Müller et al., 2011).

\section{TEMPERATURE-DEPENDENT HOMEOSTATIC ADJUSTMENTS OF PHYSIOLOGICAL PARAMETERS IN MAINTAINING STABLE SYNAPTIC TRANSMISSION}

Distinct from the above examples of synaptic homeostasis, our study reports a different category of synaptic plasticity upon long-term exposure to an environmental stressor, i.e., HT. This reflects an intrinsic ability of neuromuscular adaptation to ensure animal survival at stressful temperatures. Although the HTinduced increase in synaptic bouton numbers results in larger whole-cell synaptic currents (EJCs) (Sigrist et al., 2003), the EJP size recorded intracellularly in the postsynaptic muscle retains a level similar to that in RT-reared larvae (Ueda and $\mathrm{Wu}, 2012$; Figure 1). Our data provide an explanation: A larger synaptic current does not lead to an increase in synaptic potential owing to a corresponding decrease in muscle input resistance.

Our results show that the postsynaptic current generated by each bouton actually remains unaltered following chronic HT exposure, as evidenced by constant sizes of the focal EJC and mEJC, indicating no changes in quantal content for the release from individual boutons (Figure 2C). The mEJP amplitude is nevertheless reduced due to a lower input resistance of the muscle membrane (Figure 3). Therefore, upon arrival of each action potential, the ensemble number of transmitter vesicles released from the axonal terminal is increased because of a 
larger number of NMJ boutons, but this does not cause a larger postsynaptic muscle EJP due to a counterbalancing decrease in muscle input resistance. The simplest explanation is that long-term HT exposure induces the coordinated growth of both presynaptic nerve terminals and post-synaptic muscle such that a stable synaptic efficacy or muscle response is maintained. At present time, it is unclear whether the muscle growth precedes the nerve terminal ramification or the other way round during the process of HT-induced homeostatic adjustment, a topic that awaits further investigation.

These findings are largely consistent with previously publications (Sigrist et al., 2003; Berke et al., 2013), which reported NMJ overgrowth and increased EJC quantal content following HT treatment. However, it should be noted that in the voltage-clamp study of EJCs, Sigrist et al. (2003) did not report a decrease in the muscle input resistance of HT-reared larvae, i.e., the input resistance is about $6 \mathrm{Mohm}$, independent of rearing temperature. In contrast, our measurements based on current injection were 9.6 and 6.6 Mohm for RT- and HT-reared WT larvae, respectively (Figure 3). The reason for this difference is unknown. However, we note that the input resistance and mEJP amplitude for individual muscle fibers are highly variable, as evidenced from the ranges of data reported here (Figures 1, 3). Thus, we base our conclusions on measurements from large samples of muscle fibers that met a stringent resting potential criterion to exclude muscles with membrane damage (see Section Materials and Methods).

Decreases in larval muscle input resistance have also been observed following acute heat treatments (Barclay and Robertson, 2003) or high-frequency nerve stimulation (Gertner et al., 2014), again highlighting the parallel between the effects of HT and hyperexcitability (Sigrist et al., 2003; Zhong and Wu, 2004). However, in these cases the input resistance decrease can be observed within a relatively short time period of a few tens of minutes, distinct from our long-term rearing effect following days of HT exposure. Acute heat-treatment results in decrease in both muscle input resistance and time constant (Barclay and Robertson, 2003), indicating no drastic changes in the total membrane capacitance (proportional to membrane area; Hille, 2001) of the muscle fiber. In contrast, our study does not indicate a HT rearing-induced change in membrane time constant (Figure 3C), reflecting an increase in effective membrane area without altering passive membrane properties (Hille, 2001) of the muscle fiber.

Interestingly, high-frequency $(20 \mathrm{~Hz})$ nerve activity is equally effective in decreasing larval muscle cell input resistance within a few tens of minutes (Gertner et al., 2014). Notably, this stimulus frequency is comparable to motor neuron firing rates during fictive locomotor activity in dissected larval preparations (Budnik et al., 1990; Fox et al., 2006; Chouhan et al., 2010). Also, the decline in the input resistance involves $\mathrm{Ca}^{2+}$-dependent mechanisms since it is suppressed by genetic or pharmacological perturbations in a $\mathrm{Ca}^{2+}$-activated $\mathrm{K}^{+}$(SK) channels or $\mathrm{Ca}^{2+}$ dependent protein phosphatase 2A (Gertner et al., 2014). Interestingly, the $r u t^{1}$ mutation used in our study also abolishes the $\mathrm{Ca}^{2+}$-dependence of AC activity (Dudai and Zvi, 1984; Livingstone et al., 1984).

\section{RUT AC IN SYNAPTIC HOMEOSTASIS AND NEURAL PLASTICITY AT DIFFERENT TIME SCALES}

We found that decreases in muscle input resistance following HT rearing were not observed in rut mutant larvae defective in $\mathrm{AC}$, suggesting a role of cAMP in the homeostatic regulation mechanisms. In parallel, previous reports also document that rut mutations suppress HT-induced enhancement in neuronal growth, including dissociated neurons in culture (Peng et al., 2007), larval NMJ arbors (Zhong and Wu, 2004; Lee and $\mathrm{Wu}, 2010$ ), and adult mushroom body neurons (Peng et al., 2007). These findings demonstrate the importance of cAMP signaling in the long-term adjustment of neuronal growth and function.

It should be noted that rut AC appears to be pervasively involved in different forms of activity-dependent neural plasticity, spanning a wide range of time scales, from seconds and minutes to hours and days. Within the range of seconds, activitydependent, short-term plasticity of synaptic efficacy is well known to be altered by mutations of rut and dunce (dnc, encoding cAMP-specific phosphodiesterase), such as synaptic facilitation or depression at larval NMJs (Zhong and Wu, 1991; Renger et al., 2000; Ueda and Wu, 2009). Imaging studies of dissociated neurons in both $d n c$ and rut cultures have also demonstrated altered growth cone motility (Kim and $\mathrm{Wu}, 1996)$ and abnormal $\mathrm{Ca}^{2+}$ transients in different neuronal compartments in the time frame of seconds (Berke and Wu, 2002). At more extended time scales of minutes, $d n c$ and rut mutations affect activity-dependent recruitment of synaptic vesicles from the reserve pool (Kuromi and Kidokoro, 2000) and post-tetanic potentiation of transmitter release (Zhong and Wu, 1991) at the larval NMJ, as well as the habituation process of the jump-and-flight escape reflex mediated by the adult giant fiber (Engel and Wu, 1996).

With its wide ranging effects on activity-dependent neuronal plasticity, it is not surprising that the rut NMJs display detectable alterations in basic transmission properties. In addition to modified synaptic facilitation mentioned above (see also Figure 6), rut NMJs are known to have a range of alterations even at RT. For example, $\mathrm{Ca}^{2+}$ imaging demonstrates that influx through $\mathrm{Ca}^{2+}$ channels is more sensitive to $\mathrm{Co}^{2+}$ blockade; focal loose-patch recording reveals that vesicular release of transmitter appears to lack synchrony; and ultrastructural studies demonstrate a reduced number of docked vesicles and an increased area of synaptic density (Renger et al., 2000; Ueda and $\mathrm{Wu}, 2009)$. In the present study, we observed a tendency of increased frequency of spontaneous mEJP (compare Figures 1D and 5D) and decreased augmentation (Figure 6) in rut larvae reared at RT. HT rearing further modifies some of these altered properties, including a reduction in $\mathrm{mEJP}$ frequency and a decrease in release efficacy, i.e., reduced quantal content (Figure 5).

For different forms of neuronal plasticity, the role of rut AC may vary in terms of the exact molecular mechanisms and cellular compartments of its action. As reported above, the Gal4UAS experiments raise the possibility of rut AC involvement in pre- and post-synaptic interactions for the HT-induced synaptic homeostasis. We present below a comparison of hyperexcitabilityand HT-induced synaptic homeostatic regulations that involve 
a diversity of molecular players and cellular mechanisms orchestrated by cAMP signaling in the pre- and post-synaptic compartments.

\section{HYPEREXCITABILITY- AND HT-INDUCED HOMEOSTATIC REGULATION OF SYNAPTIC FUNCTION DURING DEVELOPMENT}

On the developmental time scale of hours to days, cAMP plays an important role in HT rearing- or hyperexcitability-induced overgrowth of nerve terminals. As described above, HT-rearing increases synaptic bouton numbers in WT larvae, which is suppressed by rut mutations (Zhong and Wu, 2004). Similarly, hyperexcitability mutations of various $\mathrm{K}^{+}$channels are known to promote nerve terminal overgrowth at the NMJ (reviewed in Fox et al., 2005). These $\mathrm{K}^{+}$channels include Eag or Kv10 encoded by ether a-go-go (eag, Warmke et al., 1991), Shaker or Kv1 encoded by Shaker (Sh, Kamb et al., 1987; Papazian et al., 1987; Pongs et al., 1988), Slo BK encoded by slowpoke (slo, Atkinson et al., 1991), and Erg or Kv11 encoded by seizure (sei, Titus et al., 1997; Wang et al., 1997). In many of these cases, the mutational effects on NMJ synaptic overgrowth are further enhanced by increased cAMP levels in $d n c$ mutant backgrounds but suppressed by defective AC activity in rut mutant backgrounds (Zhong et al., 1992; Lee and Wu, 2010).

Importantly, HT rearing also further enhances the potency of NMJ overgrowth in several of these $\mathrm{K}^{+}$channel mutations, including Sh (Zhong and $\mathrm{Wu}, 2004$ ) as well as slo and sei (Lee and $\mathrm{Wu}, 2010$ ). The same is true for HT treatment on hyperexcitability-induced neurite overgrowth in the adult mushroom body, as well as cultured neurons of eag and Sh mutants (Peng et al., 2007). Our findings of the HT rearinginduced decrease in muscle input resistance accompanying synaptic bouton growth adds another dimension of the rut AC action on homeostatic functional matching between the pre- and post-synaptic elements.

The apparent parallel between the effects of hyperexcitability and HT rearing may be deceptive in terms of their underlying molecular and cellular mechanisms, even though rut AC plays important role in both cases. The hyperexcitable slo mutants have been studied in great detail for their pre- and post-synaptic readjustments to attain synaptic stability (Lee et al., 2008). Presynaptic terminals in slo mutants lack the critical regulation by $\mathrm{Ca}^{2+}$-activated $\mathrm{K}^{+}(\mathrm{BK})$ channel to terminate $\mathrm{Ca}^{2+}$ influx for transmitter release. However, EJPs in slo NMJs are nearly normal. Therefore, it may be instructive to contrast the two types of synaptic homeostatic mechanisms, one induced by HT rearing and the other by hyperexcitability, to illustrate their distinct homeostatic adjustments to pre- and post-synaptic components (Figure 7).

Figure 7A illustrates the pre- and post-synaptic homeostasis mechanisms induced by slo BK channel mutations to highlight the corresponding physiological readjustments for achieving stability of synaptic transmission (Lee et al., 2008). The surprising finding of nearly normal EJP sizes in slo mutants reveals a compensatory upregulation of a 4 -AP sensitive $\mathrm{K}^{+}$current (likely Shaker $\mathrm{I}_{A}$ ) for the defective BK currents. In addition, a re-composition of postsynaptic transmitter receptor GluRII (ratio between A and B

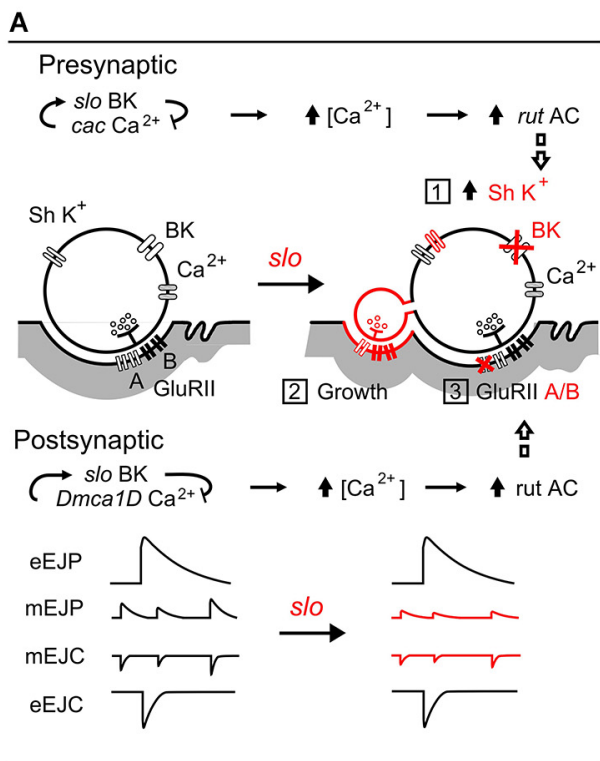

FIGURE 7 | Comparisons between slo hyperexcitabilty mutation- and HT rearing-induced synaptic homeostasis. (A) slo mutation-induced pre- and post-synaptic homeostatic adjustment (Lee et al., 2008, 2013; Lee and Wu, 2010): (1) upregulation of presynaptic $S h I_{A} K^{+}$currents to compensate for the loss of slo BK currents, (2) growth of excessive, functional satellite boutons, and (3) altered GluRII receptor composition (subunit A vs. B ratio) resulting in decreased mEJP amplitude. The roles of cac and Dmca1D $\mathrm{Ca}^{2+}$ channels, as
B
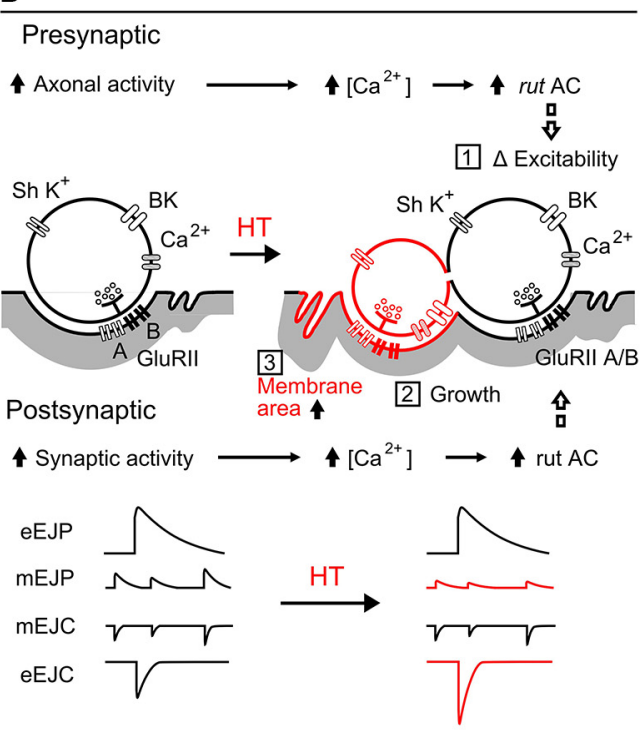

well as the rut AC-mediated adjustments are depicted. (B) HT rearing induced-homeostasis: (1) regulation of excitability by rut $\mathrm{AC}$ (Ueda and Wu, 2009), (2) increased number of boutons (Zhong and Wu, 2004; Berke et al., 2013), and (3) decreased muscle membrane resistance from increased effective muscle membrane area. The resultant modifications in amplitudes of mEJPs and EJPs are summarized. In both (A) and (B), rut AC plays an important role in homeostatic regulation of both synaptic function and growth 
subunits) leads to reduced mEJP and mEJC sizes. Even though slo induces extensive overgrowth of functional satellite boutons, the combined effects of these two adjustments partially restore the EJP size (Figure 7A, Points 1, 2, and 3). It is important to note that one of the characteristic features of rut AC action is its dependence on activity-dependent $\mathrm{Ca}^{2+}$ influx (Dudai and Zvi, 1984; Livingstone et al., 1984), presynaptically through the cac $\mathrm{Ca}^{2+}$ channels and postsynaptically through Dmca1D $\mathrm{Ca}^{2+}$ channels (Lee et al., 2013). In rut mutants, neither pre- nor postsynaptic homeostatic adjustments occur (Lee et al., 2008).

In contrast, as shown in Figure 7B, the HT-rearing induced synaptic bouton overgrowth is counterbalanced by an increase in muscle membrane area. HT rearing does not change the properties of individual boutons, and hence does not cause alterations in mEJC size. However, mEJP size is decreased due to a decrease in muscle input resistance, presumably owing to an increase in membrane area. Although the increase in bouton numbers leads to more vesicle release (increased quantal content) and larger EJC size, it is counterbalanced by the decreased input resistance to produce a nearly normal sized EJP, the ultimate whole-cell functional parameter of neuromuscular transmission.

A number of issues still remain to be further investigated in terms of the down-stream targets of rut AC in these two cases of synaptic homeostasis. Several well-established molecular networks that function in the larval NMJ should facilitate the endeavor to work out the molecular framework for different cases of HT rearing- and hyperexcitability-induced synaptic homeostasis. It has been shown that cAMP-dependent protein kinase (PKA) mediates protein phosphorylation and plays a role in larval NMJ synaptic function, with mutations of PKA subunits partially reflecting $d n c$ or rut defects (Renger et al., 2000). Furthermore, manipulations of cAMP response element binding protein CREB have been shown to control synaptic growth at larval NMJs (Davis et al., 1996; Schuster et al., 1996).

\section{ACKNOWLEDGMENTS}

The authors would like to thank Anthony McGregor for his assistance in the preparation of this manuscript. This work was supported by NIH grants GM088804 and GM080255.

\section{REFERENCES}

Atkinson, N. S., Robertson, G. A., and Ganetzky, B. (1991). A component of calcium-activated potassium channels encoded by the Drosophila slo locus. Science 253, 551-555. doi: 10.1126/science. 1857984

Baines, R. A., Uhler, J. P., Thompson, A., Sweeney, S. T., and Bate, M. (2001). Altered electrical properties in Drosophila neurons developing without synaptic transmission. J. Neurosci. 21, 1523-1531.

Barclay, J. W., and Robertson, R. M. (2003). Role for calcium in heat shockmediated synaptic thermoprotection in Drosophila larvae. J. Neurobiol. 56, 360371. doi: 10.1002/neu.10247

Berke, B., Wittnam, J., McNeill, E., Van Vactor, D. L., and Keshishian, H. (2013). Retrograde BMP signaling at the synapse: a permissive signal for synapse maturation and activity-dependent plasticity. J. Neurosci. 33, 17937-17950. doi: 10.1523/JNEUROSCI.6075-11.2013

Berke, B., and Wu, C.-F. (2002). Regional calcium regulation within cultured Drosophila neurons: effects of altered cAMP metabolism by the learning mutations dunce and rutabaga. J. Neurosci. 22, 4437-4447.

Budnik, V., Zhong, Y., and Wu, C.-F. (1990). Morphological plasticity of motor axons in Drosophila mutants with altered excitability. J. Neurosci. 10, 3754-3768.
Bushey, D., and Cirelli, C. (2011). From genetics to structure to function: exploring sleep in Drosophila. Int. Rev. Neurobiol. 99, 213-244. doi: 10.1016/b978-0-12387003-2.00009-4

Chouhan, A. K., Zhang, J., Zinsmaier, K. E., and Macleod, G. T. (2010). Presynaptic mitochondria in functionally different motor neurons exhibit similar affinities for $\mathrm{Ca}^{2+}$ but exert little influence as $\mathrm{Ca}^{2+}$ buffers at nerve firing rates in situ. J. Neurosci. 30, 1869-1881. doi: 10.1523/JNEUROSCI.4701-09.2010

Davis, G. W. (2006). Homeostatic control of neural activity: from phenomenology to molecular design. Annu. Rev. Neurosci. 29, 307-323. doi: 10.1146/annurev. neuro.28.061604.135751

Davis, G. W., and Bezprozvanny, I. (2001). Maintaining the stability of neural function: a homeostatic hypothesis. Ann. Rev. Physiol. 63, 847-869. doi: 10. 1146/annurev.physiol.63.1.847

Davis, G. W., Schuster, C. M., and Goodman, C. S. (1996). Genetic dissection of structural and functional components of synaptic plasticity. III. CREB is necessary for presynaptic functional plasticity. Neuron 17, 669-679. doi: 10 . 1016/s0896-6273(00)80199-3

Desai, N. S., Cudmore, R. H., Nelson, S. B., and Turrigiano, G. G. (2002). Critical periods for experience-dependent synaptic scaling in visual cortex. Nat. Neurosci. 5, 783-789. doi: 10.1038/nn878

DiAntonio, A., Petersen, S. A., Heckmann, M., and Goodman, C. S. (1999). Glutamate receptor expression regulates quantal size and quantal content at the Drosophila neuromuscular junction. J. Neurosci. 19, 3023-3032.

Dudai, Y., and Zvi, S. (1984). Adenylate cyclase in the Drosophila memory mutant rutabaga displays an altered $\mathrm{Ca}^{2+}$ sensitivity. Neurosci. Lett. 47, 119-124. doi: 10 . 1016/0304-3940(84)90416-6

Engel, J. E., and Wu, C.-F. (1996). Altered habituation of an identified escape circuit in Drosophila memory mutants. J. Neurosci. 16, 3486-3499.

Engel, J. E., and Wu, C.-F. (2009). Neurogenetic approaches to habituation and dishabituation in Drosophila. Neurobiol. Learn. Mem. 92, 166-175. doi: 10. 1016/j.nlm.2008.08.003

Feng, Y., Ueda, A., and Wu, C.-F. (2004). A modified minimal hemolymph-like solution, HL3.1, for physiological recordings at the neuromuscular junctions of normal and mutant Drosophila larvae. J. Neurogenet. 18, 377-402. doi: 10. 1080/01677060490894522

Fox, L. E., Soll, D. R., and Wu, C.-F. (2006). Coordination and modulation of locomotion pattern generators in Drosophila larvae: effects of altered biogenic amine levels by the tyramine $\beta$ hydroxlyase mutation. J. Neurosci. 26, 14861498. doi: 10.1523/jneurosci.4749-05.2006

Fox, L. E., Ueda, A., Berke, B., Peng, I.-F., and Wu, C.-F. (2005). "Movement disorders in Drosophila mutants of potassium channels and biogenic amine pathways," in Animal Models of Movement Disorders, ed M. LeDoux (Burlington, MA: Elsevier Academic Press), 487-504.

Frank, C. A., Kennedy, M. J., Goold, C. P., Marek, K. W., and Davis, G. W. (2006). Mechanisms underlying the rapid induction and sustained expression of synaptic homeostasis. Neuron 52, 663-677. doi: 10.1016/j.neuron.2006. 09.029

Frank, C. A., Pielage, J., and Davis, G. W. (2009). A presynaptic homeostatic signaling system composed of the Eph receptor, ephexin, cdc42 and Cav2.1 calcium channels. Neuron 61, 556-569. doi: 10.1016/j.neuron.2008. 12.028

Friedlander, M. J., Kotchabhakdi, N., and Prosser, C. L. (1976). Effects of cold and heat on behavior and cerebellar function in goldfish. J. Comp. Physiol. A 112, 19-45. doi: 10.1007/bf00612674

Gertner, D. M., Desai, S., and Lnenicka, G. A. (2014). Synaptic excitation is regulated by the postsynaptic dSK channel at the Drosophila larval NMJ. J. Neurophysiol. 111, 2533-2543. doi: 10.1152/jn.00903.2013

Goold, C. P., and Davis, G. W. (2007). The BMP ligand gbb gates the expression of synaptic homeostasis independent of synaptic growth control. Neuron 56, 109 123. doi: 10.1016/j.neuron.2007.08.006

Groh, C., Tautz, J., and Rössler, W. (2004). Synaptic organization in the adult honey bee brain is influenced by brood-temperature control during pupal development. Proc. Natl. Acad. Sci. U S A 101, 4268-4273. doi: 10.1073/pnas. 0400773101

Harri, M., and Florey, E. (1979). The effects of acclimation temperature on a neuromuscular system of the crayfish, Astacus leptodactylus. J. Exp. Biol. 78, 281-293.

Hille, B. (2001). Ion Channels Of Excitable Membranes. (Vol. 507) Sunderland, MA: Sinauer. 
Jones, J. C., Helliwell, P., Beekman, M., Maleszka, R., and Oldroyd, B. P. (2005). The effects of rearing temperature on developmental stability and learning and memory in the honey bee, Apis mellifera. J. Comp. Physiol. A Neuroethol. Sens. Neural Behav. Physiol. 191, 1121-1129. doi: 10.1007/s00359-005-0035-z

Kahsai, L., and Zars, T. (2011). Learning and memory in Drosophila: behavior, genetics and neural systems. Int. Rev. Neurobiol. 99, 139-167. doi: 10.1016/b9780-12-387003-2.00006-9

Kamb, A., Iverson, L. E., and Tanouye, M. A. (1987). Molecular characterization of Shaker, a Drosophila gene that encodes a potassium channel. Cell 50, 405-413. doi: 10.1016/0092-8674(87)90494-6

Kim, Y.-T., and Wu, C.-F. (1996). Reduced growth cone motility in cultured neurons from Drosophila memory mutants with a defective cAMP cascade. J. Neurosci. 16, 5593-5602.

Kirov, S. A., Petrak, L. J., Fiala, J. C., and Harris, K. M. (2004). Dendritic spines disappear with chilling but proliferate excessively upon rewarming of mature hippocampus. Neuroscience 127, 69-80. doi: 10.1016/j.neuroscience.2004.04. 053

Kurdyak, P., Atwood, H. L., Stewart, B. A., and Wu, C.-F. (1994). Differential physiology and morphology of motor axons to ventral longitudinal muscles in larval Drosophila. J. Comp. Neurol. 350, 463-472. doi: 10.1002/cne.9035 00310

Kuromi, H., and Kidokoro, Y. (2000). Tetanic stimulation recruits vesicles from reserve pool via a cAMP-mediated process in Drosophila synapses. Neuron 27, 133-143. doi: 10.1016/s0896-6273(00)00015-5

Lee, J., Ueda, A., and Wu, C.-F. (2008). Pre- and post-synaptic mechanisms of synaptic strength homeostasis revealed by slowpoke and Shaker $\mathrm{K}^{+}$ channel mutations in Drosophila. Neuroscience 154, 1283-1296. doi: 10.1016/j. neuroscience.2008.04.043

Lee, J., Ueda, A., and Wu, C.-F. (2013). Distinct roles of Drosophila cacophony and DmcalD $\mathrm{Ca}^{2+}$ channels in synaptic homeostasis: genetic interactions with slowpoke $\mathrm{Ca}^{2+}$-activated $\mathrm{BK}$ channels in presynaptic excitability and postsynaptic response. Dev. Neurobiol. 74, 1-15. doi: 10.1002/dneu.22120

Lee, J., and Wu, C.-F. (2010). Orchestration of stepwise synaptic growth by $\mathrm{K}^{+}$and $\mathrm{Ca}^{2+}$ channels in Drosophila. J. Neurosci. 30, 15821-15833. doi: 10. 1523/JNEUROSCI.3448-10.2010

Leslie, K. R., Nelson, S. B., and Turrigiano, G. G. (2001). Postsynaptic depolarization scales quantal amplitude in cortical pyramidal neurons. J. Neurosci. 21:RC170.

Lissin, D. V., Gomperts, S. N., Carroll, R. C., Christine, C. W., Kalman, D., Kitamura, M., et al. (1998). Activity differentially regulates the surface expression of synaptic AMPA and NMDA glutamate receptors. Proc. Natl. Acad. Sci. U S A 95, 7097-7102. doi: 10.1073/pnas.95.12.7097

Livingstone, M. S., Sziber, P. P., and Quinn, W. G. (1984). Loss of calcium/calmodulin responsiveness in adenylate cyclase of rutabaga, a Drosophila learning mutant. Cell 37, 205-215. doi: 10.1016/00928674(84)90316-7

Marder, E., and Goaillard, J.-M. (2006). Variability, compensation and homeostasis in neuron and network function. Nat. Rev. Neurosci. 7, 563-574. doi: 10. 1038/nrn1949

Merickel, M., and Kater, S. B. (1974). Neuronal change: compensatory acclimation of the contribution of an electrogenic pump to the resting potential. J. Comp. Physiol. 94, 195-206. doi: 10.1007/bf00611867

Müller, M., and Davis, G. W. (2012). Transsynaptic control of presynaptic $\mathrm{Ca}^{2+}$ influx achieves homeostatic potentiation of neurotransmitter release. Curr. Biol. 22, 1102-1108. doi: 10.1016/j.cub.2012.04.018

Müller, M., Pym, E. C. G., Tong, A., and Davis, G. W. (2011). Rab3-GAP controls the progression of synaptic homeostasis at a late stage of vesicle release. Neuron 69, 749-762. doi: 10.1016/j.neuron.2011.01.025

O’Brien, R. J., Kamboj, S., Ehlers, M. D., Rosen, K. R., Fischbach, G. D., and Huganir, R. L. (1998). Activity-dependent modulation of synaptic AMPA receptor accumulation. Neuron 21, 1067-1078. doi: 10.1016/s08966273(00)80624-8

Papazian, D. M., Schwarz, T. L., Tempel, B. L., Jan, Y. N., and Jan, L. Y. (1987). Cloning of genomic and complementary DNA from Shaker, a putative potassium channel gene from Drosophila. Science 237, 749-753. doi: 10. $1126 /$ science. 2441470

Paradis, S., Sweeney, S. T., and Davis, G. W. (2001). Homeostatic control of presynaptic release is triggered by postsynaptic membrane depolarization. Neuron 30, 737-749. doi: 10.1016/s0896-6273(01)00326-9
Peng, I.-F., Berke, B. A., Zhu, Y., Lee, W.-H., Chen, W., and Wu, C.-F. (2007). Temperature-dependent developmental plasticity of Drosophila neurons: cellautonomous roles of membrane excitability, $\mathrm{Ca}^{2+}$ influx and cAMP signaling. J. Neurosci. 27, 12611-12622. doi: 10.1523/jneurosci.2179-07.2007

Pérez-Otaño, I., and Ehlers, M. D. (2005). Homeostatic plasticity and NMDA receptor trafficking. Trends Neurosci. 28, 229-238. doi: 10.1016/j.tins.2005. 03.004

Petersen, S. A., Fetter, R. D., Noordermeer, J. N., Goodman, C. S., and DiAntonio, A. (1997). Genetic analysis of glutamate receptors in Drosophila reveals a retrograde signal regulating presynaptic transmitter release. Neuron 19, 12371248. doi: 10.1016/s0896-6273(00)80415-8

Pongs, O., Kecskemethy, N., Müller, R., Krah-Jentgens, I., Baumann, A., Kiltz, H. H., et al. (1988). Shaker encodes a family of putative potassium channel proteins in the nervous system of Drosophila. EMBO J. 7, 1087-1096.

Popov, V. I., and Bocharova, L. S. (1992). Hibernation-induced structural changes in synaptic contacts between mossy fibres and hippocampal pyramidal neurons. Neuroscience 48, 53-62. doi: 10.1016/0306-4522(92)90337-2

Popov, V. I., Bocharova, L. S., and Bragin, A. G. (1992). Repeated changes of dendritic morphology in the hippocampus of ground squirrels in the course of hibernation. Neuroscience 48, 45-51. doi: 10.1016/0306-4522(92) 90336-z

Ranganayakulu, G., Schulz, R. A., and Olson, E. N. (1996). Wingless signaling induces nautilus expression in the ventral mesoderm of the Drosophila embryo. Dev. Biol. 176, 143-148. doi: 10.1006/dbio.1996.9987

Rao, A., and Craig, A. M. (1997). Activity regulates the synaptic localization of the NMDA receptor in hippocampal neurons. Neuron 19, 801-812. doi: 10. 1016/s0896-6273(00)80962-9

Renger, J. J., Ueda, A., Atwood, H. L., Govind, C. K., and Wu, C.-F. (2000). Role of cAMP cascade in synaptic stability and plasticity: ultrastructural and physiological analyses of individual synaptic boutons in Drosophila memory mutants. J. Neurosci. 20, 3980-3992.

Roelandse, M., and Matus, A. (2004). Hypothermia-associated loss of dendritic spines. J. Neurosci. 24, 7843-7847. doi: 10.1523/jneurosci.2872-04.2004

Roots, B. I., and Prosser, C. L. (1962). Temperature acclimation and the nervous system in fish. J. Exp. Biol. 39, 617-629.

Schuster, C. M., Davis, G. W., Fetter, R. D., and Goodman, C. S. (1996). Genetic dissection of structural and functional components of synaptic plasticity. II. Fasciclin II controls presynaptic structural plasticity. Neuron 17, 655-667. doi: 10.1016/s0896-6273(00)80198-1

Sigrist, S. J., Reiff, D. F., Thiel, P. R., Steinert, J. R., and Schuster, C. M. (2003). Experience-dependent strengthening of Drosophila neuromuscular junctions. J. Neurosci. 23, 6546-6556.

Stewart, B. A., Atwood, H. L., Renger, J. J., Wang, J., and Wu, C. F. (1994). Improved stability of Drosophila larval neuromuscular preparations in haemolymphlike physiological solutions. J. Comp. Physiol. A 175, 179-191. doi: 10. 1007/bf00215114

Stewart, B. A., Schuster, C. M., Goodman, C. S., and Atwood, H. L. (1996). Homeostasis of synaptic transmission in Drosophila genetically altered nerve terminal morphology. J. Neurosci. 16, 3877-3886.

Stühmer, W., Roberts, W. M., and Almers, W. (1983). “The loose patch clamp," in Single-Channel Recording, eds B. Sakmann and E. Neher (New York, NY: Plenum Publishing Corporation), 123-132.

Tang, L. S., Goeritz, M. L., Caplan, J. S., Taylor, A. L., Fisek, M., and Marder, E. (2010). Precise temperature compensation of phase in a rhythmic motor pattern. PLoS Biol. 8:e1000469. doi: 10.1371/journal.pbio.1000469

Tang, L. S., Taylor, A. L., Rinberg, A., and Marder, E. (2012). Robustness of a rhythmic circuit to short- and long-term temperature changes. J. Neurosci. 32, 10075-10085. doi: 10.1523/JNEUROSCI.1443-12.2012

Tautz, J., Maier, S., Groh, C., Rössler, W., and Brockmann, A. (2003). Behavioral performance in adult honey bees is influenced by the temperature experienced during their pupal development. Proc. Natl. Acad. Sci. U S A 100, 7343-7347. doi: 10.1073/pnas.1232346100

Titus, S. A., Warmke, J. W., and Ganetzky, B. (1997). The Drosophila erg $\mathrm{K}^{+}$channel polypeptide is encoded by the seizure locus. J. Neurosci. 17, 875-881.

Torroja, L., Packard, M., Gorczyca, M., White, K., and Budnik, V. (1999). The Drosophila $\beta$-amyloid precursor protein homolog promotes synapse differentiation at the neuromuscular junction. J. Neurosci. 19, 7793-7803. 
Turrigiano, G. G., Leslie, K. R., Desai, N. S., Rutherford, L. C., and Nelson, S. B. (1998). Activity-dependent scaling of quantal amplitude in neocortical neurons. Nature 391, 892-896. doi: 10.1038/36103

Turrigiano, G. G., and Nelson, S. B. (2004). Homeostatic plasticity in the developing nervous system. Nat. Rev. Neurosci. 5, 97-107. doi: 10.1038/ nrn 1327

Ueda, A., and Wu, C.-F. (2009). Role of rut adenylyl cyclase in the ensemble regulation of presynaptic terminal excitability: reduced synaptic strength and precision in a Drosophila memory mutant. J. Neurogenet. 23, 185-199. doi: 10. 1080/01677060802471726

Ueda, A., and Wu, C.-F. (2012). Cyclic adenosine monophosphate metabolism in synaptic growth, strength and precision: neural and behavioral phenotypespecific counterbalancing effects between $d n c$ phosphodiesterase and rut adenylyl cyclase mutations. J. Neurogenet. 26, 64-81. doi: 10.3109/01677063. 2011.652752

von der Ohe, C. G., Darian-Smith, C., Garner, C. C., and Heller, H. C. (2006). Ubiquitous and temperature-dependent neural plasticity in hibernators. J. Neurosci. 26, 10590-10598. doi: 10.1523/jneurosci.2874-06. 2006

Wang, X., Reynolds, E. R., Déak, P., and Hall, L. M. (1997). The seizure locus encodes the Drosophila homolog of the HERG potassium channel. J. Neurosci. 17, 882-890.

Warmke, J., Drysdale, R., and Ganetzky, B. (1991). A distinct potassium channel polypeptide encoded by the Drosophila eag locus. Science 252, 1560-1562. doi: $10.1126 /$ science. 1840699

Watt, A. J., van Rossum, M. C. W., MacLeod, K. M., Nelson, S. B., and Turrigiano, G. G. (2000). Activity coregulates quantal AMPA and NMDA currents at neocortical synapses. Neuron 26, 659-670. doi: 10.1016/s0896-6273(00) 81202-7
Zars, T., Fischer, M., Schulz, R., and Heisenberg, M. (2000). Localization of a shortterm memory in Drosophila. Science 288, 672-675. doi: 10.1126/science.288. 5466.672

Zhong, Y., Budnik, V., and Wu, C.-F. (1992). Synaptic plasticity in Drosophila memory and hyperexcitable mutants: role of cAMP cascade. J. Neurosci. 12, 644-651.

Zhong, Y., and Wu, C.-F. (1991). Altered synaptic plasticity in Drosophila memory mutants with a defective cyclic AMP cascade. Science 251, 198-201. doi: 10. 1126/science.1670967

Zhong, Y., and Wu, C.-F. (2004). Neuronal activity and adenylyl cyclase in environment-dependent plasticity of axonal outgrowth in Drosophila. J. Neurosci. 24, 1439-1445. doi: 10.1523/jneurosci.0740-02.2004

Conflict of Interest Statement: The authors declare that the research was conducted in the absence of any commercial or financial relationships that could be construed as a potential conflict of interest.

Received: 31 October 2014; accepted: 08 January 2015; published online: 02 February 2015.

Citation: Ueda $A$ and $W u$ C-F (2015) The role of cAMP in synaptic homeostasis in response to environmental temperature challenges and hyperexcitability mutations. Front. Cell. Neurosci. 9:10. doi: 10.3389/fncel.2015.00010

This article was submitted to the journal Frontiers in Cellular Neuroscience.

Copyright (C) 2015 Ueda and Wu. This is an open-access article distributed under the terms of the Creative Commons Attribution License (CC BY). The use, distribution and reproduction in other forums is permitted, provided the original author(s) or licensor are credited and that the original publication in this journal is cited, in accordance with accepted academic practice. No use, distribution or reproduction is permitted which does not comply with these terms. 